\title{
A história oral das revoltas do centro de socioeducação de Londrina II: uma interpretação teórico-filosófica
}

\author{
The oral history of revolts from Londrina socioeducation center II: a philosophic theoretical
} interpretation

\author{
Ítalo Leandro Silva * \\ Olegna de Souza Guedes **
}

\begin{abstract}
Resumo:
Este artigo realiza uma interpretação teórico-filosófica sobre a trajetória de uma instituição disciplinar, denominada Centro de Socioeducação II, localizada no município de Londrina - Paraná, destinada à aplicação de medidas socioeducativas de privação de liberdade. Apresenta os resultados de uma pesquisa qualitativa fundada nos métodos da História Oral e realizada junto aos protagonistas dessa história, que é marcada pela violência das revoltas e pelos esforços empregados para contê-las. A revolta é interpretada como fruto da desrazão, como sublevação de forças e como resultado da insegurança geral na instituição que a levou a uma situação de guerra de todos contra todos. Vários são os elementos que colaboram para a manutenção do clima de "calmaria" pelo qual a instituição passa atualmente.
\end{abstract}

Palavras-chave: História oral. Revolta. Medo. Violência. Medidas socioeducativas.

\begin{abstract}
:
This article presents a theoretical and philosophical interpretation about the trajectory of a disciplinary institution, called Socioeducation Center II, located in Londrina - Paraná, for application of educational measures of deprivation of liberty. Show the results from a qualitative research founded on Oral History methods and realized close the protagonists of this history, which is marked by revolts violence and by employed efforts to contain it. The revolt is interpreted how dis-reason produce, how powers sublevations and how results of institutional general insecurity which let it one war of all against all situation. Many are the elements who collaborate for the "calm" clime maintenance the institution actually.
\end{abstract}

Keywords: Oral history. Revolt. Awe. Violence. Educational measures.

\footnotetext{
*Educador Social no Centro de Socioeducação II Londrina; Graduado em Filosofia e Especialista em Gestão de Centros de Socioeducação pela Universidade Estadual de Londrina. italoleandrosilva@hotmail.com

** Docente do curso de graduação em Serviço Social e Pós Graduação em Política Social da Universidade Estadual de Londrina; doutora em Serviço Social pela PUC-SP. olegnasg@gmail.com
} 


\section{Introdução}

Este artigo é fruto de pesquisa sobre a trajetória de uma instituição socioeducativa, designada para a execução de medidas de privação de liberdade, que apresenta em sua trajetória um histórico de violência e revoltas e de diversos esforços empregados para contê-las. Violência somente visível nas revoltas quando alcançavam os telhados da instituição; que para ser contida demandou o emprego de muitos esforços, também entendidos como "reformas", dentre os quais se destacam as realizadas nos recursos humanos, por meio da realização de concurso público para preenchimento do quadro de funcionários; na reforma da estrutura física da instituição, após a destruição do prédio em uma rebelião; na reforma da proposta político-pedagógica institucional. Todas estas reformas se inscrevem sob a ótica da relação entre o medo e a (in)segurança.

As investigações compreendem o período de Julho de 2004 à Maio de 2007: da inauguração até a última revolta registrada, quando a instituição passa por um período de calmaria e estabilidade. Entretanto, ela foi palco de revoltas e rebeliões, de situações críticas e violentas e de reações imediatas perante estas situações. Esta pesquisa nutre-se da curiosidade em torno deste período, procurando reconstituir esta trajetória, da revolta à calmaria, para mostrar o que aconteceu e quais foram as mutações que transformaram a realidade institucional. Foram empregadas três fontes distintas de conhecimento: 1) a jornalística; 2) a história oral; e 3) a literária. Com a fonte jornalística, responde-se qual a versão oficial. A história oral revela as versões dos atores desta história, sujeitos desta pesquisa, e a literária auxilia na construção das bases e fundamentos desta história, desdobrando-se entre as convocadas do campo filosófico e a literatura específica sobre as medidas socioeducativas.

O primeiro procedimento metodológico consiste na pesquisa realizada no site do jornal Folha de Londrina, o de maior circulação na cidade, e procedeu com a criação de um arquivo com as reportagens sobre a instituição daquele período. Estes recortes formaram uma fonte documental deste artigo, na qual se observa a versão oficial dos fatos. Em especial, destacam-se as reportagens que retratam os episódios das revoltas ocorridas. Alguns trechos dessas reportagens estão transcritos para que o leitor possa compará-las com a versão dos fatos obtida pelos depoimentos coletadas pela História Oral. 
A segunda etapa construiu uma fonte por meio das ferramentas e técnicas de entrevista da História Oral, que permitiram o registro das vozes das testemunhas vivas da trajetória institucional - da inauguração até os dias mais recentes. A escolha por esta metodologia deve-se ao fato de sermos também um dos protagonistas nessa trajetória, como funcionário da instituição desde setembro de 2006, o que nos coloca em contato direto com as testemunhas, inserindo-nos na chamada história do tempo presente, a qual privilegia os depoimentos orais como fonte de conhecimento, conforme ressaltado por Ferreira (2002, p. 324). Assim se registra a versão não oficial da história da instituição. A História Oral permite a reflexão sobre o registro dos fatos nas vozes dos próprios protagonistas; sua abrangência pedagógica e interdisciplinar tem papel importante na interpretação do imaginário e das representações sociais. Este artigo é inserido na dita História Oral Temática, na qual as entrevistas têm caráter temático, podendo ser realizadas com um grupo de pessoas sobre um determinado tema na forma de depoimentos (FREITAS, 2002, p. 21). A História Oral pode ser interpretada a partir das definições oferecidas por dois diferentes pesquisadores da área:

\footnotetext{
[A História Oral] é um método de pesquisa que utiliza a técnica da entrevista e outros procedimentos articulados entre si, no registro da narrativa da experiência humana. [...] devido ao uso de recursos eletrônicos, a história oral é técnica e fonte, por meio das quais se produz o conhecimento (FREITAS, 2002, p. 18).

História Oral é um recurso moderno usado para elaboração de documentos, arquivamento e estudos referentes à experiência social de pessoas e de grupos. Ela é sempre uma história do tempo presente e também reconhecida como história viva (MEIHY, 1996, p. 13).
}

Foram coletados depoimentos de um grupo de sujeitos sobre as revoltas e reformas por eles vivenciadas. Estes foram escolhidos, entre os funcionários, de acordo com o caráter de potenciais testemunhas e de participação nos eventos para os quais se voltam à pesquisa e, para tanto, foi fundamental o período em que atuaram na instituição: da inauguração em Julho de 2004 até a última revolta em 2007. Assim, coletou-se depoimentos de três funcionários, de um universo de cinco sujeitos com essas características, aqui chamados como colaborador 1, colaborador 2 e colaborador 3 . Tais sujeitos atuam nos setores de saúde e de segurança. Os depoimentos, coletados por meio 
de gravador digital (tipo mp3), foram transcritos conforme as técnicas da História Oral. As entrevistas foram conduzidas seguindo um roteiro com questões formuladas a partir das seguintes categorias: recursos humanos, ferramentas político-pedagógicas, estrutura física e da ótica da violência como fruto da relação entre medo e (in)segurança.

As fontes literárias desdobram-se entre a literatura filosófica e a literatura técnica e configuram o último procedimento metodológico, formando a base teórico-filosófica deste artigo. No texto há referências a alguns pensadores, convocados para auxiliar a reflexão sobre a revolta e a violência na instituição, dentre os quais estão: Michel Foucault, com elementos para se entender as instituições disciplinares, o poder que nelas se manifesta e as forças que nelas se sublevam; Albert Camus, que reflete sobre o sentido filosófico da revolta como o fruto da desrazão e como prova da solidariedade humana; e Thomas Hobbes, que apresenta os elementos originados da violência traduzida como "irmã gêmea" do medo. Há também referências ao Estatuto da Criança e do Adolescente e, notadamente, à coletânea de textos Cadernos do IASP, publicadas pelo Estado do Paraná em 2006.

\section{A instituição}

A instituição, denominada Centro de Socioeducação de Londrina II (CENSE Londrina II), é uma das unidades para execução de medidas socioeducativas de privação de liberdade do estado do Paraná. Foi inaugurada em 01 de Julho de 2004, batizada como Unidade Social Oficial de Internação de Londrina (USOIL), popularmente conhecida como "Educandário". Sua construção objetivava melhorar o atendimento socioeducativo voltado para as medidas de privação de liberdade, pois o Centro Integrado de Atendimento ao Adolescente Infrator (CIAADI), atual CENSE I, não comportava mais a demanda, apresentando problemas com a superlotação. A obra, executada de setembro de 2002 a julho de 2004, numa área de 1.717,81 metros quadrados, teve inicialmente capacidade para oitenta adolescentes (GALÃO, 2004). Situada na Rodovia João Alves da Rocha Loures, 5930, na zona sul da cidade; vizinha de duas instituições penitenciárias: a Penitenciária Estadual de Londrina II e a Casa de Custódia de Londrina.

Conforme os Cadernos do IASP, as ferramentas político-pedagógicas da instituição se constituem pelo conselho disciplinar, pelo estudo de caso e pelo plano personalizado 
de atendimento:

O conselho disciplinar constitui-se em um dos instrumentos pedagógicos para o desenvolvimento do adolescente no Centro de Socioeducação, porque coloca o limite, a norma e a disciplina a serviço da emancipação do educando [...] (INSTITUTO DE AÇÃO SOCIAL DO PARANÁ, 2006a, p. 70).

O estudo de caso é o próprio adolescente, a sua história, as suas características, os afetos e desafetos, os encontros e desencontros, as rivalidades, os envolvimentos na prática de atos infracionais que marcaram sua vida (INSTITUTO DE AÇÃO SOCIAL DO PARANÁ, 2006a, p. 51).

O PPA é definido como o plano de trabalho que dá instrumentalidade para o desenvolvimento pessoal e social do adolescente em cumprimento de medida socioeducativa [...]. É, também, a possibilidade do adolescente [...] iniciar a mudança do rumo de sua história, apropriar-se de sua vida e ter a chance de projetá-la desvinculada do mundo da criminalidade [...] (INSTITUTO DE AÇÃO SOCIAL DO PARANÁ, 2006a, p. 59).

O conselho disciplinar utiliza sistematicamente o código de normas e sanções disciplinares, elaborado com base na proposta pedagógica do CENSE. A aplicação do código de normas e sanções disciplinares torna possível classificar as condutas de acordo com a gravidade e frequência das faltas disciplinares cometidas. As normas representam tudo o que não é permitido ao adolescente na instituição. A norma classifica as faltas, de acordo com sua natureza, em leve, média ou grave e determina qual medida disciplinar poderá se aplicada: advertência verbal, repreensão, suspensão ou restrição de recompensas, suspensão de visita e recolhimento configuram o quadro de medidas disciplinares. O conselho disciplinar deve considerar as situações que justificam, atenuam ou agravam o cometimento da falta para se decidir pela sanção (INSTITUTO DE AÇÃO SOCIAL DO PARANÁ, 2006b, p. 53-57).

As ferramentas político-pedagógicas utilizadas pela instituição estão em consonância com a interpretação realizada por Foucault (2004) sobre as instituições disciplinares. Estas possuem como característica o exercício do poder disciplinar por meio da utilização de instrumentos simples como a vigilância hierárquica, o exame e a sanção normalizadora. Com estes instrumentos, instituições como o CENSE II Londrina visam, em sua ação educativa, a correção, ou seja, a formação e transformação do comportamento dos indivíduos. O objetivo das ações num Centro de Socioeducação é transformar o comportamento desses jovens, de modo a reverter a direção de suas trajetórias de vida 
(INSTITUTO DE AÇÃO SOCIAL DO PARANÁ, 2006b, p. 6).

Segundo Machado (1998), o poder disciplinar constitui-se de técnicas que se ajustam e se inter-relacionam de acordo com a instituição que as utiliza. É um poder polivalente que se manifesta sob quatro formas: econômica, política, jurídica e epistemológica (FOUCAULT, 2005, p. 120-122). Tais formas podem ser observadas na instituição em foco, com a exceção da econômica, pois a instituição não visa lucro ou benefícios financeiros.

É possível interpretar o poder político investido na figura do diretor e dos educadores sociais, os guardiões da instituição. Este poder permite ordenar, aplicar medidas, tomar decisões, estabelecer regulamentos, aceitar ou expulsar os indivíduos. A figura do diretor é essencial para a aplicação da disciplina, pois ele opera orientando os funcionários e ditando os rumos da instituição. Encontra-se no topo da vigilância hierárquica e deve saber tudo o que acontece, suas decisões refletem diretamente no trabalho realizado pelos funcionários e no comportamento dos adolescentes (isto ficará claro nos depoimentos dos sujeitos).

O conselho disciplinar pode ser interpretado como símbolo do poder judiciário, o qual é uma espécie de microtribunal que julga permanentemente de acordo com os comportamentos: onde se pune ou se recompensa, classifica-se e se avalia os indivíduos (FOUCAULT, 2005, p. 120). Constitui a sanção normalizadora, expressa no código de normas e sanções disciplinares, explanado anteriormente.

O estudo de caso "[...] é um método de análise qualitativa usado como meio de organizar dados, preservando o caráter unitário do objeto estudado" (INSTITUTO DE AÇÃO SOCIAL DO PARANÁ, 2006a, p. 52). Numa interpretação desta ferramenta, pode-se apontá-la como a expressão do poder epistemológico na instituição, com o qual constrói um saber sobre os adolescentes, por exemplo, sua biografia, suas motivações, seus anseios, suas expectativas. É o exame do adolescente pelos diversos profissionais da instituição, à medida que deles obtêm um saber individualizado (personalizado) que nasce da observação, do registro, da classificação, da análise e comparação dos comportamentos (FOUCAULT, 2005, p. 121). 


\title{
Um cotidiano de revoltas, de medo e de reações imediatas
}

A revolta neste artigo, entre os diversos sentidos e significados possíveis, é sinônimo de rebelião, de crise, de desordem. ${ }^{1}$ Significa os momentos mais críticos e instáveis da instituição, na qual se verifica um histórico em que os adolescentes internos se insurgiam contra a situação à que se viam submetidos. O momento da revolta é a tomada da instituição pelos adolescentes, é momento de confusão, de desordem e caos, de destruição, de fugas, de tomada de reféns, de violência. Enfim, é também um momento de luta, de resistência e de guerra.

$\mathrm{Na}$ perspectiva do pensador francês Albert Camus, em $\mathrm{O}$ Homem Revoltado, encontra-se uma interessante concepção da revolta:

\begin{abstract}
A revolta nasce do espetáculo da des-razão diante de uma situação injusta e incompreensível. Mas seu ímpeto cego reivindica a ordem no meio do caos e a unidade no próprio seio daquilo que foge e desaparece. [...] Sua preocupação é transformar. Mas transformar é agir, e agir, amanhã, será matar, enquanto ela ainda não sabe se matar é legítimo (CAMUS, 2003, p. 21).
\end{abstract}

Para Camus, a solidariedade é uma certeza filosófica ao passo que é uma das características da revolta. Na revolta, o homem abandona seu egoísmo e dá as mãos ao seu semelhante. A revolta pode ser individual (do oprimido) ou coletiva (daqueles que assistem à opressão de outro), num movimento catártico. ${ }^{2} \mathrm{~A}$ revolta é o protesto contra a condição humana injusta e incompreensível (BARRETO, 1970). A revolta exemplifica-se na atitude de Prometeu ${ }^{3}$ Acorrentado que, solidário aos homens vivendo em situação de

\footnotetext{
${ }^{1}$ São as situações classificadas como eventos críticos. Segundo o Caderno do IASP, intitulado "Gerenciamento de Crises nos Centros de Socioeducação", para classificar um evento como crítico deve-se observar o seguinte: a presença de armas brancas ou armas de fogo; a participação de dois ou mais setores; a proporção de insurgentes deve ser de o dobro de educadores sociais; os focos de incêndio são incontroláveis pelos funcionários; todo setor afetado é destruído; há casos graves de lesão: ameaça à vida; a presença de reféns com necessidade de negociação especializada, agressões diretas aos funcionários; possibilidade de morte ou fato consumado (PARANÁ, 2006c, p. 21).

2 Catarse: expressão utilizada na interpretação sobre Aristóteles a respeito do efeito "purificador" que os espetáculos teatrais provocavam nos espectadores, levando-os a se identificarem com o personagem e seu destino trágico.

${ }^{3}$ De acordo com a mitologia grega, Prometeu é um dos titãs, uma raça de gigantes que habitou a terra antes do homem. Ele participou da criação do homem e foi responsável por torná-lo superior aos outros animais. Para isto, subiu aos céus, acendeu sua tocha ao carro do sol e confiou o domínio do fogo ao homem. Assim, foi possível ao homem superar aos animais com a construção de armas e de ferramentas (BULFINCH, 2006, p. 24). Em Prometeu Acorrentado, o poeta grego Ésquilo narra as dores de Prometeu ao ser castigo nos confins da terra, onde, como castigo dos deuses pelo seu feito, foi acorrentado e tinha o fígado devorado diariamente por pássaros carnívoros.
} 
ignorância, ensina-lhes o domínio do fogo.

Destaca-se a interpretação de revolta que Artières (2004) realiza sobre o pensamento de Foucault. Para ele, a revolta assume a forma de uma erupção de forças, de uma sublevação, pois os detentos, porque humilhados, usados e explorados, tornamse uma força perante a administração da instituição:

Ao ocupar o lugar estratégico dos telhados, os motins podiam ser vistos e ouvidos; a revolta não tinha por objetivo a destruição da prisão ou a fuga, mas reivindicações muito precisas, exigências simples, às vezes mínimas, que incidiam sobre a rotina da detenção (ARTIÈRES, 2004, p. 19).

A revolta camusiana como desrazão e ato solidário e a revolta foucaultiana como erupção de forças e sublevação não se confundem com a revolução comunista expressa no Manifesto Comunista por Marx e Engels, em 1848. A revolta camusiana não se preocupa de modo imediato com as questões políticas e sociais, não nasce apenas do oprimido, seja ele um indivíduo ou uma classe social, nasce de qualquer ser humano que vive em condições de humilhação e de sofrimento imposto por outro (BARRETO, 1970). Já a revolução é caracterizada como uma luta entre duas classes: a burguesia e o proletariado. Luta que se transforma em motim, em ataque às relações burguesas de produção, em destruição de mercadorias estrangeiras, destruição das máquinas, de incêndios às fábricas. Enfim, a revolução é uma luta social que tem o mesmo caráter em toda parte, é uma luta de classes, é uma luta política (MARX, 1997). Não se pode confundir a luta operária, revolucionária com a revolta foucaultiana, nem mesmo pensar que a revolta expressa na rebelião está para uma fronte revolucionária (ARTIÈRES, 2004). A revolta como uma sublevação pode ser fruto de uma situação cotidiana injusta, no intuito de torná-la visível, de levá-la para fora dos muros da instituição. Certamente os rebelados não visavam à tomada ou à inversão das relações de poder e sim denunciar as iniquidades e opressões a que eram submetidos, mesmo que não conseguissem traduzilas de forma inteligível devido à própria desrazão que caracteriza o ato da revolta.

Diante das perspectivas que a revolta assume neste artigo, trata-se de passar para os resultados da investigação realizada com os métodos da História Oral. As entrevistas realizadas com três colaboradores da instituição revelaram aspectos muito interessantes sobre o cotidiano institucional. Cotidiano este marcado pelas revoltas, pelo medo e pelas 
reações imediatas dos funcionários frente à emergência da violência e da necessidade de contê-la. Por reações imediatas compreende-se, de forma análoga, a ação de apagar incêndios, de apagar o fogo ateado na instituição. Vários aspectos coletados nas entrevistas não apareceram nas informações obtidas pelos recortes de jornais. Os depoimentos, em sua maioria, contradizem as informações publicadas pela imprensa, como o leitor poderá constatar.

Com relação à trajetória da instituição, ela será reconstruída por meio da análise das categorias observadas nos depoimentos, da apresentação dos recortes de jornal e pelas interpretações dos fatos com base em nossos pressupostos teórico-filosóficos. E um primeiro aspecto dessa reconstrução refere-se a seus recursos humanos. Constatou-se que o pessoal contratado pelo teste seletivo não tinha experiência de trabalho com adolescentes privados da liberdade e com a vida institucional. Isto juntamente com a insuficiente capacitação que Ihes forneceram são fatores importantes nos rumos de violência, iniquidades e revoltas que marcaram a história da instituição. Nessa acepção, destaca-se o seguinte depoimento:

Tivemos uma capacitação de uma ou duas semanas, uma coisa muito supérflua, de que nada realmente chegava perto do que seria a realidade que nós conhecemos posteriormente... Eram pessoas novas e, inclusive, a maioria sendo o primeiro emprego destas pessoas. As pessoas não tinham noção do que era uma vida institucional, de uma vida dentro de uma organização (Colaborador 3).

O Estatuto da Criança e do Adolescente (BRASIL, 2006) prevê a medida socioeducativa de internação em estabelecimento educacional (Art. 112, VI e Art. 124, XI). Entretanto, a instituição não garantia aos adolescentes o acesso à escola, devido à ausência de professores no quadro de pessoal. As atividades se resumiam na oferta de algumas oficinas e jogos de tabuleiro:

Na época eram só as oficinas mesmo. Nós éramos seis pessoas. A maioria na verdade não sabia fazer nada. Então era um filme que se passava. Os jogos... Vinham bastantes jogos de tabuleiro que a gente levava para os meninos [...] outra dava aquela cestaria de jornal. Estas coisas assim. Aula não tinha... Tentei usar a quadra, mas também não tinha como. Eles pulavam o muro para o solário. Então a quadra também não era usada. Não tinha quase nada (Colaborador 2). 
Havia carência de pessoal no setor de saúde, fator que dificultava os atendimentos: "A gente não tinha médico, não tinha nada... quer dizer o pessoal da enfermagem tinha que dar conta de tudo o que estava acontecendo" (Colaborador 1 ).

Os depoimentos revelaram o isolamento da instituição em relação à administração do (instinto) Instituto de Ação Social do Paraná (IASP) e da Secretaria de Trabalho, Emprego e Promoção Social (SETPS), com sede em Curitiba:

A administração não dava suporte. Cada vez ficava mais claro isto aí, que realmente a gente estava totalmente isolado... Também a falta de apoio institucional do IASP, do governo (Colaborador 3).

Às vezes a gente começou a ter problemas aqui dentro, você ligava e chegavam até a desligar o telefone na nossa cara, quando você entrava em contato com Curitiba (Colaborador 1).

Revelaram também a falta de uma liderança, de uma pessoa capacitada para o trabalho socioeducativo, de alguém que lhes ensinassem a controlar o "fogo".

[...] Tinha o pessoal dos educadores, tinha os técnicos então acho que a gente foi o que ficou mais perdido, porque não tinha ninguém para orientar a gente (Colaborador 2).

Nós não tínhamos uma liderança (Colaborador 3).

A instituição foi apelidada por "castelo de areia", devido à má qualidade da construção. Os internos conseguiam atravessar as paredes dos alojamentos utilizando objetos e água e até mesmo as próprias mãos para isto, dado importante para compreendermos a necessidade das reformas no prédio. Nos seguintes depoimentos, pode-se observar tais aspectos:

Eles mesmos falavam: - "isto aqui é areia pura". Os adolescentes mais inseguros ficavam "J., R., C. isto aqui é um castelo de areia, olha só passa a unha e sai". Eles conseguiam raspar toda esta argamassa da parede com a unha. [...] Cavavam inclusive o vaso sanitário, até no concreto do chão mesmo. Quebravam o vaso sanitário e com os cacos eles quebravam mais ainda [...] e achavam a terra e começavam a cavar muita terra. Então virou esse apelido "castelo de areia" porque ela não tinha cimento (Colaborador 3).

Eles pegavam a escova de dente e água, [...] e cavoucavam as paredes! E, era fácil! Era de um alojamento para o outro. Era para fora. Passava por trás estava à mãozinha do menino lá. Era frágil, né? (Colaborador 2). 
O cotidiano de medo e a (in)segurança vivenciada na instituição é nítida nos depoimentos. As situações de fugas, nas quais os adolescentes serravam misteriosamente as grades, alimentavam a imaginação dos sujeitos, fazendo-os sempre temer o pior e, com isto, viverem desconfiados de todos:

\begin{abstract}
As fugas mesmo, que aconteciam eram porque conseguiam serrar as grades que davam acesso para o lado de fora. O grande mistério era como que essas serras entravam. Ou eram visitas ou, provavelmente, eram funcionários que entregavam essas serrinhas para os adolescentes... $O$ adolescente conseguia intimidar, conseguia entrar na mente de alguns educadores e faziam com que eles trouxessem ou drogas ou serrinhas, no caso. Tínhamos o maior medo de entrar uma arma ali. Quando o adolescente resolve fugir com uma serrinha, por mais que todos fiquem preocupados não tem muito perigo para os educadores. Às vezes a gente imaginava isso: se entrasse uma arma ali, era uma coisa que a gente ficava bastante preocupado... A gente estava num ambiente totalmente inseguro, não se podia confiar em ninguém: nem na segurança (Colaborador 3).
\end{abstract}

As brigas e rixas, a presença de "seguros", a falta de autoridade, o desrespeito aos educadores e a fragilidade do prédio aumentavam o clima de medo e insegurança na instituição:

\begin{abstract}
Os adolescentes não respeitavam. O funcionário não tinha autoridade sobre estes adolescentes. Eram muitos xingamentos, muitos xingamentos mesmo. [...] estoques começavam a aparecer. De todos os lugares saíam estoques [...] E os educadores eram ameaçados, e começaram a jogar muitas coisas nos educadores. Começamos a ter também adolescentes seguros. E começamos a entender a realidade daquele adolescente. [...]. As intrigas da rua começaram a aparecer ali dentro também... Não tínhamos um sistema direito de medidas disciplinares. Mas o que mais realmente pecava naquela época realmente, olhando de hoje, era a falta de imposição do educador para com os adolescentes. E perdiam o limite. E aí a gente começou a perder, é claro, o controle da unidade (Colaborador 3).
\end{abstract}

Os funcionários, nesse cenário, não se entendiam, não dialogavam, pois estavam sem direção: "Era todo mundo num barco à deriva... Não tinha um norte... Era quase uma Babel isso aqui..." (Colaborador 1). As relações entre a equipe de educadores e a equipe técnica também eram conflituosas: "Acho que é aquela coisa: técnico passa a mão na cabeça e o educador quer a disciplina... Antes não tinha conversa, era um contra o outro

\footnotetext{
${ }^{4}$ Os "seguros" são os adolescentes que precisam de proteção especial dos funcionários para a garantia de sua integridade. Geralmente são acusados de crimes como estupro, são alcaguetes, quebraram as regras do crime etc.
} 
mesmo" (Colaborador 2).

O medo, a insegurança, a falta de respeito e a violência permitem aproximar o cotidiano da instituição ao estado de natureza hobbesiano, que se traduz no estado generalizado de conflitos violentos nas relações entre os sujeitos. Para Hobbes (1974, p. 79):

[...] os homens não tiram prazer algum da companhia uns dos outros (e sim, pelo contrário, um enorme desprazer), quando não existe um poder capaz de manter a todos em respeito. [...] De modo que na natureza do homem encontramos três causas principais de discórdia. Primeiro, a competição; segundo, a desconfiança; e terceiro, a glória. A primeira leva os homens a atacar os outros tendo em vista o lucro; a segunda, a segurança; e a terceira, a reputação. Os primeiros usam a violência para se tornarem senhores das pessoas, mulheres, filhos e rebanhos dos outros homens; os segundos, para defendê-los; e os terceiros por ninharias [...] Com isto se torna manifesto que, durante o tempo em que os homens vivem sem um poder comum capaz de os manter a todos em respeito, eles se encontram naquela condição que se chama guerra; e uma guerra que é de todos contra todos os homens (grifo nosso).

Nessas condições de insegurança e de medo, a violência se manifestava de diversas formas: nos xingamentos, nas agressões, na depredação do prédio, enfim, nas rebeliões. A revolta, fruto da desrazão, da injustiça e incompreensão geradas pelas situações de desconfiança e medo, expressa nas rebeliões a guerra de todos contra todos. A violência da revolta atrela-se, assim, à busca de segurança e respeito, de ordem e paz: "O estado de natureza é uma condição de guerra, porque cada um se imagina (com razão ou sem) poderoso, perseguido, traído" (RIBEIRO, 1989, p. 60).

É nesse contexto que se gesta e que se manifesta a primeira rebelião na história da instituição. Para ilustrá-la, destaca-se uma reportagem publicada pela Folha de Londrina sobre a primeira revolta na instituição, ocorrida pouco mais de um mês de sua inauguração, em 9 de Agosto de 2004:

Para IASP, abstinência provocou a rebelião: transferências para a unidade de internação foram suspensas; diretor afirma que local é seguro.

Uma crise de abstinência química foi a causa da rebelião provocada anteontem pelos adolescentes infratores internados na Unidade Social Oficial de Internação de Londrina [...] Anteontem, [...] quatro internos estouraram o cadeado do alojamento. Utilizando o extintor de incêndio, eles destruíram os cadeados das outras celas. Armados com estiletes e estoques feitos a partir de objetos que eles teriam arrancado das paredes e de equipamentos eletrônicos, a maioria dos 49 adolescentes conseguiu sair dos alojamentos e ganhar o 
telhado da instituição. A rebelião só foi debelada [...] quando 40 homens do Pelotão de Choque da Polícia Militar entraram na instituição. Eles utilizaram bombas de efeito moral e balas de borracha. [...] Os internos quebraram os rebocos das paredes e tentaram arrancar as grades das celas. As luminárias e os televisores do refeitório também foram destruídos. Por medida de segurança, a diretoria decidiu suspender o banho de sol e as atividades educativas. [...] 0 diretor do IASP admitiu que pode ter sido precipitado transferir tantos menores em pouco tempo. Nos últimos dias, seis adolescentes chegavam à unidade diariamente. [...] Souza insistiu que a USOIL é segura e não houve incompetência dos funcionários para evitar a rebelião [...] A USOIL pode receber até 80 adolescentes e tem, como filosofia de atuação, a humanização do atendimento. Os internos têm acompanhamento médico, odontológico e psicológico [...] frequentam cursos profissionalizantes, oficinas de artes e artesanatos, além de participarem de atividades esportivas (VICENTINI, 2004).

Os adolescentes revoltados sobem aos telhados e inauguram na trajetória da instituição sua primeira rebelião. Marcada pela violência e pelo medo, é uma revolta que denuncia os problemas cotidianos da instituição, fruto da série de dificuldades e das incompreensões que se davam entre os muros e as grades da instituição. Um dos colaboradores comenta sobre o medo e a violência por ele testemunhada neste dia:

O que eu lembro, quando eu cheguei estavam todos aqui em baixo. Os educadores e o diretor. Ninguém tinha coragem de subir. E assim foi. Os meninos começaram a quebrar tudo. Eu saí e fiquei do lado de fora olhando. Tinha menino no telhado, um batendo no outro... (Colaborador 2).

Nestes depoimentos ficaram claras as enormes dificuldades vivenciadas por nossos colaboradores na instituição no início das atividades. A revolta chama a atenção para o Educandário e a violência dos internos mostra toda a fragilidade do prédio. Entre os fatores atribuídos à erupção desta revolta, destacam-se a carência e a inexperiência do pessoal contratado, a fragilidade do prédio, a ausência de direção e de instrumentos político-pedagógicos. Tais fatores são relevantes para a instabilidade instalada na instituição e manifestada também na revolta dos próprios funcionários contra a situação na qual se encontravam. ${ }^{5}$

Entre os funcionários, a revolta surge perante as condições de medo e insegurança dentro da instituição. Os depoimentos mostram a revolta contra a administração e o sentimento de abandono pelo governo do estado. Nesta direção, é possível dizer que os

\footnotetext{
${ }^{5}$ A revolta observada entre os funcionários foi uma revelação que nos surpreendeu durante as entrevistas. Não a prevemos em nosso projeto, em que se esperava observar a revolta somente entre os adolescentes.
} 
funcionários estavam, de acordo com a perspectiva camusiana, numa situação de incompreensão da realidade que viviam, sentindo-se desrespeitados como se pode observar no seguinte depoimento:

O sentimento da equipe era de muita revolta, só que nossa revolta começou a ficar cada vez maior, só que não tão contra os adolescentes, e sim contra o IASP. Porque não atendia, falava que era assim mesmo... Lógico tinha aquele clima, você ficava com o adolescente, mas acho que a maior revolta mesmo dos funcionários era contra o governo do estado e contra a secretaria pela irresponsabilidade e pela falta de respeito que tinha com os funcionários [...] (Colaborador 1).

Após esta rebelião e os diversos problemas enfrentados com a estrutura física, com o despreparo do pessoal, com a agressividade dos adolescentes, os funcionários num ato revoltado e de solidariedade aos colegas e aos adolescentes unem-se para denunciar o que estava acontecendo na instituição:

Porque começou a dar todos estes problemas desde o início e a gente ligando para Curitiba e eles fazendo vista grossa. Aí um dia a gente perdeu a paciência e fizemos um documento e mandamos para a imprensa... Daí começou a cair um monte de gente do IASP, trocar de diretor... Porque a questão não era só a direção, era todo o conjunto que estava acontecendo (Colaborador 1).

A opressão contra os funcionários que "se revoltavam" contra a situação de irregularidades na instituição e das condições de (in)segurança para a realização das atividades é observada na demissão destas pessoas, conforme observado na interpretação de um dos sujeitos da pesquisa:

Eu acho que foi depois disto que o pessoal, os funcionários, tomaram a frente e fizeram um relatório com denúncias e tudo o que estava errado e mandaram. $O$ que acabou gerando a demissão de várias pessoas (Colaborador 2).

Daí os funcionários ficavam revoltados e eram demitidos (Colaborador 1).

Três destes funcionários demitidos, um educador social, uma assistente social e uma psicóloga, procuraram a imprensa e apresentaram um documento enviado ao Ministério Público e ao Conselho Tutelar sobre as possíveis retaliações aos direitos dos adolescentes e sobre as condições inadequadas de funcionamento da instituição (AVANSINI, 2004). Neste contexto, é movida uma ação de intervenção da instituição, 
como se observa no recorte abaixo:

Promotoria pede intervenção em Educandário: Em vez de fechar a unidade, MP estabelece prazo de seis meses para a readequação

A promotora da Vara da Infância e Juventude do Fórum de Londrina, Édina Maria de Paula, ingressou [...] com ação contra o Instituto de Ação Social do Paraná (IASP) pedindo intervenção em caráter liminar na Unidade Social Oficial de Internação [...]. Ela argumenta que a unidade estaria em desacordo com a legislação porque não dispõe de condições físicas, estruturais e de assistência capazes de promover a ressocialização dos adolescentes infratores. 0 Ministério Público pede que seja nomeado um interventor para executar a readequação da unidade dentro de seis meses. A promotora baseou-se em relatório divulgado por funcionários, em depoimentos de internos e em visita que fez ao local. O documento entregue pelos servidores demonstraria deficiências físicas e materiais e falta de treinamento adequado. [...] Sem condições de atendimento, começaram a haver "retaliações aos direitos dos internos, os quais não possuem acesso a qualquer atividade pedagógica, escolar, esportiva, cultural e profissionalizante", teriam sido proibidos de tomar banho e tiveram a suspensão ilegal de visitas. As violações teriam resultado na primeira rebelião registrada no Educandário, em 9 de agosto. [...] Édina pediu o afastamento da atual diretoria. [...] A promotora explicou [...] o objetivo não é fechar a unidade e sim promover as mudanças necessárias para garantir atendimento adequado aos internos [...] (AUGUSTO, 2004).

No processo de intervenção a Dra. Laura Keiko Sakai Okamura foi nomeada para ocupar a direção da instituição. Esta nomeação altera os rumos da instituição: "Ela foi pressionada a assumir o CENSE [USOIL] [...] tinha por muito tempo gerenciado o sistema FEBEM..." (Colaborador 3). Seu papel neste cenário é simbolizado por Prometeu, e sua importância é constatada nas memórias dos sujeitos da pesquisa. Torna-se o líder que eles precisavam: ensinando-Ihes como trabalhar, fornecendo-Ihes as ferramentas e instrumentos necessários para "controlar o fogo". Um colaborador revela como era o trabalho com ela:

A gente trabalhava doze, quatorze horas por dia. Segunda a segunda, sem problemas. A gente foi indo com a Laura, apesar de algumas pessoas acharem que o arquétipo dela era até doentio com relação a tanto trabalho assim, mas que também era necessário na unidade e a gente fazia sem problema nenhum. Era muito tempo, muito desgastante. Mas, também era prazeroso porque estávamos aprendendo muito. E como aprendemos! (Colaborador 3).

Apesar do processo de intervenção e da mudança da direção, as situações de violências perduravam, e novamente a revolta subleva-se e destrói completamente o prédio em 2 de dezembro de 2004. Sobre este fato, foi publicado: 
Internos fazem reféns e destroem o Educandário.

Os 39 adolescentes que estavam na Unidade Oficial de Internação de Londrina [...] fizeram uma rebelião no final da tarde de ontem. O prédio foi praticamente destruído e três internos teriam fugido. Segundo informações extraoficiais o prédio seria interditado hoje. O ex-interventor do Educandário, Márcio Filla, informou que, por volta do meio dia de ontem, um menor teria jogado uma pedra em um educador. O funcionário teria revidado, batendo no adolescente. [...] Segundo a vice-presidente do Conselho Tutelar Norte, Rita Bastos, os outros internos, supostamente descontentes com a agressão, teriam pego as chaves das celas e começado a quebrar a unidade. Na confusão, os garotos fizeram quatro reféns. "Todo o sistema elétrico e hidráulico foi destruído", confirmou Márcio Filla, um dos reféns. Segundo Rita Bastos, os adolescentes reclamavam de que não podiam tomar banho de sol e que estavam esperando a realização das prometidas oficinas. [...] Filla argumentou que as atividades psicopedagógicas (oficinas) já estavam sendo realizadas. Quanto ao banho de sol, ele afirmou que os adolescentes não estavam saindo das celas por causa da "reforma pedagógica" que estava sendo implantada. [...] O Pelotão de Choque da Polícia Militar (PM) foi chamado, mas não chegou a entrar no prédio. [...] Em visita ao Educandário na semana passada, o secretário do Trabalho, Emprego, e Promoção Social, padre Roque Zimermann, disse que "a unidade funcionava como um relógio" (WERLE, 2004).

A interpretação de um dos colaboradores sobre esta rebelião, que destruiu o prédio e decretou sua interdição, apresenta um sinal de alívio: "[...] do jeito que tava indo, pra nós funcionários, foi a melhor coisa que aconteceu" (Colaborador 1), motivada pela agressão de um educador social sobre um adolescente que lhe teria atirado uma pedra. O estopim dessa revolta revela o violento cotidiano de guerra vivido na instituição e corrobora a revolta camusiana como ato de solidariedade perante uma situação injusta:

Eu subi e fui até a Ala B. Quando estava voltando cruzei com um adolescente no corredor e logo que desci este adolescente deu início: pegou um educador com uma caneta e conseguiu a chance. A causa de tudo isto... Um educador deu um soco em um adolescente, que tinha problemas mentais... Este adolescente tinha jogado uma coisa nele, nas costas dele... E aí pegou este menino e bateu nele na frente dos outros, os outros se revoltaram [...]. Pegaram alguns funcionários de reféns... Eu fiquei do lado de fora. [...] Destruiu tudo aqui (Colaborador 2).

O que não foi destruído pelos adolescentes neste dia foi quebrado pelos próprios funcionários, num momento de revolta contra a qualidade da construção. A própria estrutura física retratava simbolicamente a opressão que sofriam: as mudanças eram uma emergência. As forças que se sublevavam eram retratadas em noticiários que denunciavam as péssimas condições em que eram aprisionados. 
Perdemos o controle e aí foi uma quebra geral. Os adolescentes quebraram muita coisa naquela data, porque o "socorro" do Choque demorou. Apenas isolamos o perímetro e tentamos ter cuidado para que não pegassem os "seguros", e mesmo assim pegaram e acabaram batendo nestas pessoas [...]. Enfim, quebraram muito a unidade. E alguns pontos que não foram quebrados a gente quebrou depois, porque não tinham condições de ficarem determinadas estruturas ali. Já pensando numa reforma geral [...], numa reestrutura da unidade (Colaborador 3).

Após esta revolta, a instituição foi interditada e os adolescentes transferidos para outras instituições. Entre dezembro de 2004 a abril de 2005 foram realizadas as diversas reformas e readequações na estrutura física, as quais são relatadas nos depoimentos:

A estrutura física é hoje o que você conhece na unidade. A divisão mesmo por alas, com acessos independentes. A questão dos muros que foram feitos, as telas que foram colocadas, as grades... Cobriu a quadra... Aquela quadra ali também era descoberta... Antes era um corredor só aqui onde circula o ar, então são todas as adequações mesmo para facilitar o trabalho. Não é uma planta ideal, mas dentro do que a gente tinha acabou ficando... Era um círculo só. Tinha as divisões de alas e você circulava a unidade inteira. Aonde sai para o solário descoberto ali tinha todo um muro de tijolo, aí você tinha mais ou menos um metro e meio nesse corredor, você passava até moleque com estoque te pegava no corredor, você tinha que atravessar as alas todas. Tinha um muro interno baixinho. Aqui atrás onde hoje tem um muro era uma tela... (Colaborador 1).

Nesse mesmo período, os funcionários tiveram uma capacitação melhor estruturada que foi de suma importância. Ela forneceu conhecimentos e subsídios para compreender melhor a realidade da instituição, possibilitando uma perspectiva mais técnica para o desenvolvimento do trabalho com os adolescentes, bem como o acesso a saberes que permitiram ações mais racionais e seguras:

Daí sim, a Laura organizou uma grande capacitação, que foi... de janeiro a abril. Isto todo dia, manhã e tarde. Então foi uma capacitação imensa, daí pegando todos os aspectos, questão pedagógica, questão da saúde, questão de treinamento com a polícia e bombeiros, aula de defesa pessoal. Então foi a primeira vez mesmo que a gente estava tendo uma capacitação realmente estruturada e ao mesmo tempo estava sendo reformada a unidade com os padrões de segurança necessários para o trabalho (Colaborador 1).

Acho que a capacitação ajudou bastante, principalmente a parte de segurança... (Colaborador 2). 
A instituição foi reinaugurada em abril de 2005 e rebatizada como Centro de Socioeducação, com funcionários melhores capacitados, estrutura física reformada e readequada, liderança de Laura Okamura e com uma orientação filosófico-pedagógica, que se fundamentava nos trabalhos do pedagogo Antônio Carlos Gomes da Costa. ${ }^{6}$ Sobre o fato, destaca-se a seguinte reportagem:

\begin{abstract}
Requião reinaugura Educandário
[...] Numa cerimônia que reuniu o governador [...], cinco secretários de Estado e mais de uma dezena de autoridades estaduais e municipais, foi reinaugurado ontem o educandário de Londrina, rebatizado agora de Centro de Socioeducação. A unidade [...] diminuiu sua capacidade dos originais 80 para 61 e ainda precisa de adequações pontuais. Mas a expectativa é que a partir da próxima semana comece a receber os primeiros internos com uma nova doutrina de atendimento, voltada para recuperação e ressocialização. A unidade foi inaugurada em julho do ano passado mas só acumulou problemas rebeliões, fugas e reclamações de educadores e especialistas que culminaram com a intervenção do Ministério Público e na necessidade de uma reforma completa do prédio ao custo de $\mathrm{R} \$ \mathbf{4 8 8}$ mil. Agora, com educadores mais bem treinados e o prédio e alas reestruturados, a esperança é de que o centro se transforme em uma instituição-modelo para outras cidades. [...] O secretário do Trabalho, Emprego e Promoção Social, [...] ressaltou o trabalho de reestruturação da equipe de educadores e admitiu que na primeira inauguração o treinamento dos funcionários foi insuficiente [...]. A diretora da unidade, Laura Okamura, destacou que a forma de atuação está assentada em três pontos: em uma proposta pedagógica diversificada em oficinas ocupacionais, cursos e escolarização; numa proposta funcional de uso da unidade; e no alinhamento conceitual entre os funcionários, que terão uma visão filosóficopedagógica do trabalho [...] (AUGUSTO, 2005).
\end{abstract}

Nos depoimentos pode-se observar a declaração de um dos sujeitos sobre as mudanças promovidas pela reforma, entre elas, destaca-se a implantação de uma proposta de trabalho, que não havia anteriormente:

\begin{abstract}
Mudou tudo, desde a recepção do menino... Depois da reforma. E tinha todo um trabalho [...]. Tinha um caderninho do adolescente. As técnicas iam lá passar tudo para eles. Tinha o rodízio de alas, chegava ia para uma ala depois de uma semana lotava e passava para outra. As atividades iam saindo aos poucos, depois de certo tempo... Na verdade foi feita uma proposta, que antes não tinha... Toda aquela questão do protagonismo juvenil... Da Pedagogia da Presença, do Antônio Carlos [Gomes da Costa] (Colaborador 2).
\end{abstract}

Após as reformas, as ferramentas pedagógicas começam a ser aplicados na

\footnotetext{
${ }^{6}$ Autor de livros voltados para a formação de educadores sociais: Costa e Pimentel (2001), Costa (2001a) e Costa (2001b).
} 
instituição. Inicia-se um processo de apropriação dos instrumentos político-pedagógicos. É quando se inicia a aplicação do conselho disciplinar, dos estudos de caso, dos planejamentos personalizados de atendimento:

A Laura fez reuniões para tentar organizar, para falar sobre o CD o PPA. Ela que começou a implantar estas coisas, que antes não tinha (Colaborador 2).

Nós começamos a trabalhar em cima da pedagogia da presença. Tínhamos pelo menos um fundamento no qual a gente podia se amparar. Na capacitação foi discutida a pedagogia da presença, pedagogia do oprimido, pedagogias. Tudo para entender o adolescente. Grande conhecimento da parte psicológica do adolescente foi passado para estes educadores, de como funciona aquele corpo cheio de hormônios [...] (Colaborador 3).

É importante destacar a elaboração da coletânea dos Cadernos do IASP, publicadas em 2006, utilizada como referência neste trabalho. A coletânea é composta por cinco volumes: Compreendendo o Adolescente, Práticas de Socioeducação, Gestão de Centros de Socioeducação, Rotinas de Segurança e Gerenciamento de Crise nos Centros de Socioeducação. Apresenta as diretrizes e conceitos gerais para a prática socioeducativa no Paraná:

\footnotetext{
Os conteúdos presentes nos cadernos do IASP, que refletem o aprendizado acumulado da instituição até o momento, pretendem expressar a base comum orientadora para a ação pedagógica e socioeducacional a ser desenvolvida junto aos adolescentes atendidos em nossos Centros de Socioeducação. Trata-se, portanto, de uma produção coletiva que contou com o empenho e conhecimento dos servidores do IASP, e com a aliança inspiradora da contribuição teórica dos pensadores e educadores referenciais (INSTITUTO DE AÇÃO SOCIAL DO PARANÁ, 2006a, p. 10).
}

Entre os anos de 2005, 2006 e até maio de 2007, a instituição talvez tenha passado por dias menos violentos, pois não se verifica notícias de revoltados sob o telhado da instituição. Entretanto, apesar de todos os esforços empregados para garantir a segurança e diminuir o clima de violência, em 05 de maio de 2007 mais um capítulo da história das revoltas é registrado:

\section{REBELIÃO - Madrugada de fúria no Educandário de Londrina}

Numa clara demonstração de força da delinquência juvenil, um grupo de adolescentes infratores internados no Centro de Socioeducação (CENSE) de Londrina [...] promoveu uma rebelião de sete horas. A confusão começou por 
volta das 21 horas da sexta-feira e só teve fim às 4 horas de sábado, [...] Os rebelados atearam fogo em todos os colchões, depredaram a enfermaria, o consultório odontológico e grande parte do prédio, incluindo o telhado [...] Acionada para negociar a rendição dos adolescentes rebelados, a promotora da Vara da Infância e Juventude, Édina de Paula, chegou à unidade por volta de 1h30. Antes disso, pelo menos 50 policiais militares [...] acompanhavam do lado de fora a depredação do prédio. A rebelião, segundo a promotora, teria começado por um descuido de um educador que não teria fechado corretamente uma algema durante escolta de dois internos de uma ala para outra. Ele acabou sendo rendido junto com outro colega de trabalho. [...] os adolescentes também fizeram reféns cinco adolescentes que estavam numa ala chamada de "seguro" [...] Rapidamente chegaram ao telhado, de onde gritavam palavras de ordem e tentavam intimidar os educadores e os policiais atirando pedaços de ferro. [...] Pouco mais de uma hora após o início da rebelião, o grupo de líderes liberou um dos educadores e um adolescente [...]. Pelo rádio do educador, eles ameaçavam matar os reféns, mas não faziam reivindicações mais claras ao tenente [...] para a promotora, o grupo "reclamou da comida, dos chinelos e pediu cigarro, refrigerante, pizza". [...] Apenas os bombeiros atuavam mais ativamente na tentativa de acabar com os focos de incêndio. [...] (Colaborou Fernanda Mazzini) (AUGUSTO, 2007).

Sobre esta revolta, destaca-se o depoimento de um dos colaboradores que testemunhou o início de toda a revolta naquela noite:

[...] É engraçado que depois de trabalhar algum tempo nesse ambiente você começa a ficar desconfiado de alguma coisa... Aquela noite o ambiente estava estranho, tanto é que eu cheguei para os dois e falei: "Olha, não passa colchão, não passa colchão"... Combinamos a situação: como estavam em efetivos pequenos, eles pediram para eu acompanhá-los até a Ala, [...] na contenção... Só que [...] você não consegue visualizar a contenção pela questão da parede que tem... Eu fiquei do lado de fora e eles ficaram com as chaves e falaram: "Olha, a gente sai pela lateral. Fica de olho"... Começou a demorar um pouco. Eu ouvi um barulho e tudo ficou quieto. Aí eu falei "vou dar mais um tempo, se eles não saírem eu vou chamar ajuda". Eu estava saindo, já entrando na quadra para ligar pra direção, falando que estava com algum problema, quando eu vi abrir a porta lateral. Quando eu volto, topo com dois meninos saindo também. Consegui sair rápido... Eu tomei um susto muito grande e acho que eles também, porque acho que eles não estavam esperando que tivesse alguém... Consegui descer. A nossa sorte, na época, é que tinha um policial aqui na guarita da entrada, e ele foi acionando a policia. Nesse meio tempo eu tentei subir até o PC [Posto Central] para visualizar. Foi quando os dois adolescentes tentaram me pegar, eu entrei em luta corporal com eles, daí o [...] policial viu, veio e me ajudou. Eu retornei, comecei a chamar todos os educadores e foi a confusão que deu (Colaborador 1).

Nesta rebelião a destruição da unidade foi considerada pequena, em comparação aos estragos provocados pelas revoltas anteriores, devido ao reforço estrutural realizado pelas reformas. O fato que a marcou foi a condição de reféns, a qual dois educadores sociais foram submetidos. A preocupação maior dos sujeitos era com estas pessoas: " $A$ 
gente não sabia o que tinha acontecido com estes educadores" (Colaborador 3). De acordo com um dos sujeitos, a revolta não tinha nenhuma motivação, para ele havia a sensação de justiça entre os adolescentes:

\begin{abstract}
Eles tinham uma sensação de justiça: - "A gente ta preso aqui, mas o pessoal está fazendo alguma coisa para a gente." [...] não tinha uma motivação para os adolescentes fazerem a rebelião. Eles não aprontaram, fora o fogo que colocaram lá. Pelo tamanho da coisa, eu acho que foram poucos estragos... $O$ fogo faz um estrago enorme, mas em ternos de destruição a unidade estava muito mais preparada. Alguns adolescentes subiram, mas a maioria ficou contida esperando o que ia acontecer. Fora alguns loucos mais revoltados que fizeram um estrago maior de botar fogo, de machucar os educadores (Colaborador 3).
\end{abstract}

A revolta se sublevava, tomava os telhados naquela noite e, ainda, reclamava pela ordem. Mais uma noite de violência e medo: uma "madrugada de fúria no educandário". O caos e a desordem da revolta brotavam como fruto da desrazão. Entretanto, não havia ainda o controle e autoridade dos funcionários sobre tais jovens. Os funcionários eram ainda inexperientes, ${ }^{7}$ não sabiam manipular os instrumentos político-pedagógicos e perdiam novamente o controle do "fogo". Seria preciso, ainda, aumentar a disciplina na instituição.

Esta revolta permitiu às equipes discutirem a construção de uma nova dinâmica institucional, de uma nova rotina. A divisão em grupos reduzidos de adolescentes permitiu maior controle e o desenvolvimento da autoridade dos educadores sociais, como destacado no testemunho:

Os educadores se reuniram. Os técnicos também se articularam para ver como ficava esta nova dinâmica. Mas, principalmente os educadores... Inclusive já articulando, [...], a saída de seis horas apenas do adolescente que foi o que aconteceu depois [...] eles mesmos propuseram o contra turno, para liberar um pouco mais, [...]. Então a própria percepção do educador com relação a isto, de mostrar a solução, de se envolver com isto. Foi muito interessante, muito positivo [...] O desenvolvimento da autoridade do educador. Principalmente isto. A questão de se ter controle em grupos reduzidos (Colaborador 3).

\footnotetext{
${ }^{7}$ Nesta revolta, a equipe de funcionários havia mudado consideravelmente devido à sua contratação recente por meio de Concurso Público realizado em 2006. A maioria dos funcionários não tinha conhecimento do histórico da instituição e estavam em processo de aprendizagem do trabalho.
} 
Esta foi a última revolta registrada na trajetória da instituição. São poucas as testemunhas desses dias. Muitos só conhecem aquilo que Ihes contaram. Outros vivenciaram alguns desses dias. Poucos os testemunharam desde o começo, e com suas memórias foi possível recontar a história da instituição e mostrar a guerra cotidiana que lá imperava e, por vezes, manifestava-se nos telhados. A história da instituição continua a ser escrita, mas já não é mais uma história de revoltas, sublevações, medo, violência e caos. No entanto, os sujeitos reconhecem a importância desta história para manter a calmaria na instituição:

Acho que a nossa própria história: de rebelião... De quebra-quebra, de treinamentos, anos de trabalho. Não adianta só dar capacitação. [...] Se for ver, já tem quatro anos que o povo tá aprendendo, continua aprendendo. Sempre uma hora ou outra aparece um problema que a gente não tinha e tem que resolver (Colaborador 1 ).

A disciplina afirma-se como um dos elementos fundamentais para a manutenção da calmaria na instituição desde a última revolta, como afirma um dos sujeitos "[...] é cobrado a disciplina aqui dentro [...]" (Colaborador 1). Outros fatores são funcionamento regular da escola e a oferta de outras atividades:

Eu creio que a escola aqui dentro é algo interessante, que ajuda. Quanto mais atividades você tiver, mais você vai ocupar esta pessoa. [...] Acho que isto ajuda muito. As externas: guarda-mirim, menor aprendiz [...] As atividades tem uma ótima função terapêutica. Tem hora que eu acho que tem mais fundo terapêutico do que outras coisas... (Colaborador 1).

Há, ainda, outro elemento apontado como algo que contribui para a calmaria: o controle por meio da farmacologia psiquiátrica:

[...] os moleques estão mais calmos por causa dos remédios e tal... Mas, se o remédio for necessário para ter um diálogo com ele eu acho até que pode ser utilizado (Colaborador 3).

Entretanto, apesar deste período sem revoltas, o clima de calmaria pode ser colocado em xeque a qualquer momento. Uma série de fatores, que, certamente, vão além destes observados em nossa pesquisa, podem ameaçá-lo, mas os esforços dos funcionários estão voltados para a sua manutenção. E, além disso, a experiência obtida 
com toda esta história de revoltas é útil para manter este clima:

Eu creio que a equipe aprendeu a trabalhar, [...] já esta há anos fazendo isso. $O$ perfil do adolescente está um pouco mais calmo do que alguns que a gente andou recebendo. A maior questão aí está em apreender a fazer o trabalho. Hoje os funcionários estão seguros no que estão fazendo. Apesar de que, esse tipo de trabalho, eu brinco que é sempre como um furacão, agora a gente está no olho do furacão, que é a calmaria, mas em volta está o furacão, então uma hora ou outra sempre tem algum problema e isso faz parte do trabalho (Colaborador 1).

Talvez uma situação qualquer ou uma oportunidade traga à tona novas situações em que a revolta se manifeste, em que a desrazão e a sublevação ganhem novamente os telhados da instituição, em que a violência e a guerra se instalem, o medo e a insegurança retornem, chamando novamente à atenção ao Educandário. Não é possível saber quando isto acontecerá e se acontecerá, mas é possível que aconteça. O que nos cabe, por ora, é alertar para as lições que se pode tirar de toda esta história.

\section{Considerações finais}

A história da instituição revelou uma trajetória de violência, medo, insegurança e imediatismo das intervenções nas manifestações de revoltas, de rebeliões. A instituição imprimiu vários esforços para controlar estas revoltas, que surgiam em um contexto injusto. A estrutura física não era capaz de conter a força daqueles adolescentes; a carência de pessoal para executar as atividades necessárias: educadores, professores, médicos, entre outros; a ausência das ferramentas político-pedagógicas, o sentimento de medo e de (in)segurança que reinava na origem da violência; a necessidade de uma liderança para apontar os rumos da instituição.

As revoltas que tomavam o telhado da instituição, mesmo sem qualquer reivindicação racional pelo seu próprio caráter de desrazão, denunciavam estes problemas da instituição. A visibilidade das sublevações durante as rebeliões pode ser entendida como uma chamada de atenção das autoridades, da sociedade, do estado, para a realidade da instituição. Ou seja, se há fogo e adolescentes nos telhados é sinal de que existem falhas no funcionamento da instituição. Isto não deve ser tomado como uma regra, mas como uma interpretação realizada a partir dos pensadores que nos auxiliaram 
na reconstrução da trajetória desta instituição. Nesse sentido, buscou-se corrigir tais problemas, com as reformas na estrutura física, nas ferramentas pedagógicas, na rotina implantada pelos educadores sociais com grupos reduzidos de adolescentes.

Até o momento em que escrevemos este texto, quase cinco anos após a última revolta em 2007, a instituição vivenciou pequenos momentos de violências, mas nada comparado com as revoltas destacadas. Quem conhece de perto esta história poderá questionar outras situações violentas que não apareceram aqui. Não as ignoramos, não as mostramos, pois focamos nas maiores revoltas, naquelas em que se perdeu o controle de toda a instituição, de certa forma, nas principais revoltas.

A maior surpresa nesta investigação foi constatar a revolta entre os funcionários. 0 projeto pretendia observá-la apenas entre os adolescentes, mas os funcionários foram os colaboradores desta empreita. É evidente que se poderia resgatar o ponto de vista deles. Um equívoco no projeto? Talvez. Um interessante trabalho, nesse mesmo sentido, poderia ser produzido junto aos adolescentes que participaram das rebeliões, como sujeitos de pesquisa, como testemunhas dos fatos, como uma voz do povo (ordinary people). Imensas seriam as dificuldades para a realização de tal projeto, para localizar essas pessoas, para entrevistá-las. Entretanto, com os funcionários, obteve-se uma riquíssima experiência, depoimentos surpreendentes e a oportunidade de junto deles contar-lhes esta história.

\section{Referências}

ARTIÈRES, P. O intelectual específico. In: GROS, F. (Org.). Foucault: a coragem da verdade. São Paulo: Parábola, 2004. p. 15-38.

AUGUSTO, L. Promotoria pede intervenção em Educandário. Folha de Londrina, Londrina, 5 out. 2004. Disponível em: <http://www.bonde.com.br/folha/folhad.php?id_folha=2-1-921-20041005>. Acesso em: 4 maio 2010.

. Rebelião: madrugada de fúria no educandário de londrina. Folha de Londrina, Londrina, 6 maio 2007. Disponível em:

<http://www.bonde.com.br/folha/folhad.php?id_folha=2-1--921-20041005>. Acesso em: 4 maio 2010.

Requião reinaugura educandário. Folha de Londrina, Londrina, 14 abr. 2005. Disponível em: <http://www.bonde.com.br/folha/folhad.php?id_folha=2-1--359620050414>. Acesso em: 3 dez. 2009. 
AVANSINI. C. Ex-funcionários da Usoil dizem que foram punidos. Folha de Londrina, Londrina, 25 set. 2004. Disponível em:

<http://www.bonde.com.br/folha/folhad.php?id_folha=2-1--6855-20070506>. Acesso em: 1 dez. 2009.

BARRETO, V. Camus: vida e obra. Rio de Janeiro: Paz e Terra, 1970.

BRASIL. Estatuto da criança e do adolescente. Curitiba: Imprensa Oficial, 2006.

BULFINCH, T. O livro de ouro da mitologia: histórias de deuses e heróis. Rio de Janeiro: Ediouro, 2006.

CAMUS, A. O homem revoltado. Rio de Janeiro: Record, 2003.

COSTA, A. C. G.; PIMENTEL, A. P. G. Educação e vida: um guia para o adolescente. Belo Horizonte: Modus Faciendi, 2001.

COSTA, A. C. G. Aventura pedagógica: caminhos e descaminhos de uma ação educativa. Belo Horizonte: Modus Faciendi, 2001a.

2001b.

Pedagogia da presença: da solidão ao encontro. Belo Horizonte: Modus Faciendi,

FERREIRA, M. M. História, tempo presente e história oral. Rio de Janeiro: Topoi, 2002.

FREITAS, S. M. História oral: possibilidades e procedimentos. São Paulo: Imprensa Oficial do Estado, 2002.

FOUCAULT, M. Vigiar e punir. Petrópolis: Vozes, 2004.

A verdade e as formas jurídicas. Rio de Janeiro: Nau, 2005.

GALÃO, F. O educandário estará pronto até julho, garante Decon. Folha de Londrina, Londrina, 19 jun. 2004. Disponível em:

<http://www.bonde.com.br/folha/folhad.php?id_folha=2-1--3936-20040619>. Acesso em: 1 dez. 2009.

HOBBES, T. Leviatã ou matéria, forma e poder de um estado eclesiástico e civil. São Paulo: Abril Cultural, 1974.

MACHADO, R. Por uma genealogia do poder. In: FOUCAULT, M. Microfísica do poder. Rio de Janeiro: Graal, 1998. p. 8-23.

MARX, K. O manifesto comunista. São Paulo: Paz e Terra, 1997.

MEIHY, J. C. S. B. Manual de história oral. Loyola: São Paulo, 1996.

INSTITUTO DE AÇÃO SOCIAL DO PARANÁ - IASP. Práticas de socioeducação. Curitiba, 2006a. (Cadernos do IASP) 
. Rotinas de segurança. Curitiba: Imprensa Oficial, 2006b. (Cadernos do IASP)

. Gerenciamento de crises nos centros de socioeducação. Curitiba: Imprensa

Oficial, 2006c. (Cadernos do IASP)

RIBEIRO, R. J. Hobbes: o medo e a esperança. In: WEFFORT, F. C. Os clássicos da política. São Paulo: Ática, 1989. p. 54-77

VICENTINI, C. Para IASP, abstinência provocou a rebelião. Folha de Londrina, Londrina, 11 ago. 2004. Disponível em: <http://www.bonde.com.br/folha/folhad.php?id_folha=2-1-2275-20040811>. Acesso em: 4 maio 2009.

WERLE, J. Internos fazem reféns e destroem o educandário. Folha de Londrina, Londrina, 13 dez. 2004. Disponível em: <http://www.bonde.com.br/folha/folhad.php?id_folha=2-1-1075-20041203>. Acesso em: 5 maio 2009.

Recebido em: 27/07/2011

Aprovado em: 10/10/2011 